\title{
The First Activity in Research
}

Anjana Bhattarai

\begin{abstract}
This paper aims to highlight the process of selecting a research topic through the identification of broad area and then narrowing it down to the research title. The article starts with the brief introduction to research and its micro activities. It also clarifies that topic selection is the base for all other microactivitie.The focus is laid on reviewing the literature as the preliminary step in the selection of research topic. In order to facilitate the new researchers and to remind the experienced ones, a list of some possible broad areas in applied linguistics is presented. Before concluding the article, I have argued that without reading and reviewing the existing literature topic selection is very difficult.
\end{abstract}

Key words : Research problem, research process, micro activity, broad area, specific area

\section{Introduction}

Research, in general, means to find out some new information related to certain issue. Burn (1994, p. 2) views research as "a systematic investigation to find answers to a problem.” It is a macro activity consisting of a lot of micro activities. Research can be broadly divided into two phases: planning and conducting a research study. The micro activities like formulating a research problem, conceptualizing a research design, constructing tool(s) for data collection, selecting a sample, writing a research proposal are accomplished in the former phase whereas activities like collecting data, processing data, writing and re-writing a research report are completed in the latter phase (Kumar, 2006 p. 19).

The first micro activity in any research is to formulate the research problem/question/topic because neither is available in the bookshop nor is it handed by the researcher's guide. Moreover, without finalizing it, other subsequent activities cannot be accomplished.

\section{Discussion of the issue}

The researchers have to put their effort themselves in selecting the research topic, though it is not an easy task as the novice researchers might think. Most of the beginning researchers in our university think that going through the available list of topics, selecting those which seem easy and altering some of the variables like level, gender of the respondents, level of the textbook, language group of the informants will result into a new research problem. For example, the list of theses (2009) in the Department of English Education, Tribhuvan University, shows that thesis 295 is written on Washback effects of B.Ed. examination, thesis 317 on Washback effects of the B.Ed. examination of ELT theories and methods, thesis 367 on Washback effects of secondary level listening test, thesis 375 on Washback effects of B.Ed. examination of general English, thesis 520 on Washback effects of SLC send-up examination. This list entails that in theses 295, 317, 375, research studies are carried out on the same theory for the same level only altering 
the subjects. The first one is holistic, i.e. washback effects of all subjects is studied, in the second and third, one subject each is focused upon. Similarly, both theses 367 and 520 are also limited to the same theory, same class but subject is different. Out of around 30 broad areas this is only a particular case. Maximum number of such examples can be observed under proficiency study, error analysis, textbook analysis, study on attitudes, etc.

When these novice researchers are asked the reason of this change of the variables their only answer is that they want it to look like a new topic. Being one of the members of guidance and evaluation committee I have observed that they neither examine the problem critically and nor do they defend it satisfactorily in terms of research design, sample, sampling design, research tool, process of data collection and analysis. If the guide tries to convince them about the right track of the process they feel that they are unnecessarily harassed. Gay's (1987: 31) opinion, "To the poor students it seems as if every problem he or she identifies is dismissed by their advisor as being trivial or already done" reflects students' attitude.

There is a distinct gap between sitting in the annual examinations and conducting research to complete one's Master's level. Our education system particularly at Tribhuvan University itself is creating this gap. The syllabus and the examination system control the teaching learning process. Limited number of books are prescribed in the syllabus and there is the system of only annual examination, i.e., students are not required to sit for any examination within the whole year and to write any paper to supplement their study. They attend examinations only at the end of the one academic session lasting a year. Suddenly, for their research, when they are asked to read and review more than ten written or recorded materials like articles, books, reports, and theses within a limited time, they find themselves confused, lost and look for the easy way out which is next to impossible. So they select the easy way of one or two variables based on the previously conducted study.

All researchers, whether they are new or experienced, have to follow a systematic research process. The first activity in the process tends to be formulating a research problem. Comparatively it may become easy for experienced ones, but for the beginners this is a Herculean task. Gay's (1987 p. 31) opinion strengthens this reality, "For beginning researchers, selection of a problem (topic) is the most difficult step in the research process. Some graduate students spend many anxiety-ridden days and sleepless nights worrying about where they are going to find the problem they need for their thesis. To the poor students it seems as if every problem she or he identifies is dismissed by their advisor as being trivial or already done." A similar view is expressed by Powers, Meenaghan and Twoomey (1985 p. 38), "Potential research questions may occur to us on a regular basis, but the process of formulating them in a meaningful way is not at all an easy task" (as cited in Kumar, 2005 p. 40).

Whatever is the difficulty level of formulating a research problem the researchers themselves have to go through this process. If researchers are determined to conduct research then there is no way to escape from undergoing this responsibility. Supporting this fact, Kothari (1998) writes, "Nevertheless, every researcher must find out his own salvation for research problems cannot be borrowed. A problem must spring from that researcher's mind like a plant springing from its own seed" (p.32).

Formulating a research problem is really a big challenge for the new researchers and not paying heed to their guides may increase the complexity of the task. Cautioning them, Hart (2006 p.55) says, "You can make the process difficult by ignoring the advice of your supervisors."

By now it is established that the first and the most difficult activity in research design is formulating the research problem. The researchers themselves have to do it. Without it, researchers cannot set their objectives, decide upon their methodology, research design, a sample, sampling design, research tool, method of data collection and analysis.

So it is better "Learning how and where to locate problems and systematically attacking this phase of the research process... than worrying one's self into a nervous collapse!" (Gay, 1987 p. 32). Almost 
all the experts unanimously agree upon the starting step of the formulation of research problem. It is "to identify a general problem area” for Gay (1987 p. 32 ), "to keep in mind that... the general topics that need a great deal of refinement in order to become a researchable problem" for Best and Kahn (1993 p.36), "a statement of the problem in a general way" for Hart (2005 p. 56) and "to identify a broad field or subject area of interest” for Kumar (2006 p. 44). The common factor of these views is that the researchers have to select, first, the general or broad area of their interest. The general area of interest can be selected either studying the existing theory of the discipline or observing the practice, i.e. experiencing in the work place. The beginning researchers have to mostly select those areas by studying the existing literature, i.e. theory and research works because they may not have the required level of experience.

Every discipline like sociology, physics, theoretical linguistics, applied linguistics, etc. have their own broad areas. In applied linguistics, there exist a number of those areas. To make the list short I am limiting myself to the research studies so far carried out in the Department of English Education of the Faculty of Education at Tribhuvan University. For the first time those areas were documented by Govinda Raj Bhattarai in 2001. Bhattarai identified 17 broad areas which were selected by 70 students and completed their research (2001:77). In 2005, Bal Krishna Sharma and Prem Bahadur Phyak contributed to add 7 more areas to the list. As a result there were 24 broad areas selected by 160 research students up to 2004 (Bhattarai, 2005 p. 165). Then, in 2008, Jai Raj Awasthi and Anjana Bhattarai prepared a paper for one-day orientation program in which the list has been increased up to 31 areas. However, in two previous works only bottom-up approach was used but in this paper topdown approach was also used. These areas were : error analysis, proficiency, methods of teaching, instructional materials, medium of instruction, listening skill, speaking skill, reading skill, writing skill, teaching of grammar, vocabulary, spelling, language functions, teaching of English literature, contrastive/comparative study, testing and evaluation, attitudes, translation, teachers' guide, language training, language used in electronic devices, behaviour, mass media, textbook analysis, language planning, English for specific purpose/ register, motivation, computer assisted language learning, first/second language acquisition, discourse analysis, and semantics and pragmatics. The list of this type is always open and we can add more and more areas to it. Best and Kahn (1993 p. 35) have also included the list of such broad areas. The beginning researchers who have to carry out research in English Language Teaching can select any one of the above listed broad areas. In this regard they have to keep in mind Kothari's (1998 p.32) suggestion.

i. Area which is overdone should not be normally chosen, for it will be a difficult task to throw any new light in such a case. For example, there are maximum number of works on proficiency and error analysis in the Department of English Education so students are suggested not to select these areas.

ii. Too narrow and too vague or broad problems should be avoided. For example, topics like availability and use of teachers' guide and use of interaction technique are too narrow because in the former case the researcher asks mainly two questions: whether it is available or not and it is used or not. In the latter case because of the weak possibility of the use of this technique in our context, survey research may not yield the satisfactory data. Similarly, ELT situation of Nepal and language proficiency can be divided into many components like situation of curriculum, textbook, classroom, teacher training, examination in the former case and proficiency in listening, reading, speaking, writing skills, vocabulary, spelling, any grammatical aspect in the latter case.

If the researchers pause for a while, keep the above suggestions in mind and select one of the broad areas, their initial hurdle is crossed. The second step is "dissection of the broad area into sub-areas" (Kumar, 2006 p. 45). The broad area in the writing skill can be further dissected into specific areas like techniques used to teach writing skill, materials used in teaching writing skill, learning strategies used in mastering writing skill, proficiency in 
writing skill, classroom activities in teaching writing skill. These topics are suitable for survey research. For experimental or action research the topics like project work and writing skill, brainstorming and writing skill, reading and reviewing are the suitable ones. However, this is not the final list of topics for research on writing skill. The more one reads the existing literature the better s/ he develops insight and utilizes it to frame more specific areas within one general area. Researchers should consult their guides in this stage. The first activity of research remains incomplete till it is converted into a research title. Hart (2005 p. 56) has very clearly presented the steps from the selection of the research problem to the finalizing of the title. The following flow chart of Hart (ibid.) guides the researcher to successfully decide on the research problem and then frame the title.

\section{problem and then frame the title.}

Identify an area of interest

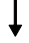

Talk to your guide

Reflect and explore possibilities

(Departmental researches, current professional issues, historical debates, work-based problems)

Identify sources of information

(Collect anything that looks interesting and useful, review the available literature)

\section{List and define key concepts and terms}

(What research has been done on the topic?

What research questions have been asked?

What methods have been used to conduct research on the topic?

What kinds of research problems are not solved in the literature?)

Frame and evaluate the title against criteria

(Is the necessary and sufficient data available? Can you get access to the data?

Do you have the skills to analyse the data?

Do you have the time, energy, patience and fund to carry out the study?)

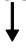

Talk to your guide, discuss and finalize the title.
The third step, as it is presented in the above flow chart, suggets to reflect on the possibility of finalising the topic. Then the fourth step suggests identifying the sources of information. The sources are books, journals, internet, research reports, and all the recorded and written information. To locate these sources is also not that easy. Researchers have to visit different libraries, scan through the catalogues available there, select one material, go through its references and scan it to locate more sources, visit different websites, locate the required information, download with full reference, etc. Sometimes individuals like teachers, friends and other people knowledgeable in the field can also give some idea. But personal study is the most reliable activity and it boosts the researcher's confidence as well. In this way, to smoothly sail through the first micro activity of research one has to very patiently read, review, contemplate on and consult the guide several times.

\section{Conclusion}

To summarize, the first activity of the process of research is to identify the research problem then translate it into the research title. To accomplish this activity the researcher can use either top-down or bottom-up approach. In top-down approach the researcher should identify one broad area out of many broad areas available in one's discipline. Then sources of study of that area have to be located. Reviewing the information from those sources, critically reflecting on what has been done so far and what can be done now one has to narrow down the broad area into a specific one. $\mathrm{S} /$ he should consult the guide for finalizing the area and then frame the topic. Thus, reading, reviewing, critically examining and executing are the integral activities of research and the same is true in the case of completing the first activity as well.

Anjana Bhattarai, a Reader in the Department of English Education, Tribhuvan University, Kirtipur, did her Masters in English literature and English Education from Tribhvan University and her M.Phil. and Ph.D. in Applied Linguistics from the Central University of Hyderabad, India. She trains English teachers of different levels, and supervises and evaluates research students of M.Ed. and M.Phil students from Tribhuvan and Kathmandu University (Nepal). She has also presented papers in national and interantional conferences. She has published three reference books to her credit, coauthored school level textbooks from Nursery level to grade VIII. Furthermore, she presented a paper in the conference of the United Nations in New York (2007). 


\section{References}

Awasthi, J.R. \& Bhattarai, A. (2008). Writing thesis proposal and thesis. Orientation paper for the students of M.Ed., Department of English Education, Kirtipur, Kathmandu.

Best, J.W. \& Kahn, J.V. (1993). Research in education (7 ${ }^{\text {th }}$ ed.). New Delhi: Prentice-Hall of India.

Bhattarai, G.R. (2001). A thematic analysis of research reports. Kathmandu : Ratna Pustak Bhandar.

Bhattarai, G.R. (2005). A thematic analysis of research reports. Kathmandu : Ratna Pustak Bhandar.

Burns, R.B. (1994). Introduction to research methods ( ${ }^{\text {nd }}$ ed.). Melbourne: Longman Cheshire.
Gay, L.R. (1987). Educational research. ( $3^{\text {rd }}$ ed.). United States of America: Merrill Publishing Company.

Hart, C. (1990). Doing your masters dissertation. New Delhi : Vistaar Publications.

Kothari, C.R. (1990). Research methodology ( $2^{\text {nd }}$ ed.). New Delhi : Wishwa Prakashan.

Kumar, R. (2005). Research methodology ( $2^{\text {nd }}$ ed.). New Delhi : Pearson Education.

Powers, G. T., Meenaghan, T. M. \& Twoomey, B. G. . (1995). Practice focused research: Integrating human practice and research. In Kumar, R. (2005). Research methodology. ( $2^{\text {nd }}$ ed.). New Delhi : Pearson Education. 